\title{
Reinvestigation of the roles of the carboxyl groups of glutathione with yeast glyoxalase I
}

\author{
Implications as to the mechanism and coenzymic role of glutathione
}

\author{
Claudius D'Silva \\ Department of Biological Chemistry, The University of Michigan, Ann Arbor, MI 48109, USA
}

Received 3 March 1986

\begin{abstract}
A number of carboxyl-substituted $S$-blocked glutathiones have been shown to be competitive inhibitors of yeast glyoxalase I at $25^{\circ} \mathrm{C}, \mathrm{pH} 6.6$. Amidation of the glycyl carboxyl group of $S$-( $p$-bromobenzyl)glutathione has no appreciable effect on binding whilst methylation reduces binding by 8.9-fold, indicating a steric constraint and the possible presence of a hydrogen bond in this region of the enzyme. Amidation of both carboxyl groups of $S$-( $p$-bromobenzyl)glutathione reduces binding significantly by 237 -fold; this result agrees with electrostatic interaction of the $\mathrm{Glu} \mathrm{COO}^{-}$group with a group located within the enzyme surface as opposed to the $\mathrm{Gly} \mathrm{COO}^{-}$group, previously proposed.
\end{abstract}

(Yeast) Glyoxalase Coenzyme analog Competitive inhibition Glutathione

\section{INTRODUCTION}

Glutathione ( $\gamma$-glutamylcysteinylglycine) fulfils a variety of roles vital to life processes. Of these roles it has gained prominence as a coenzyme which constitutes the glyoxalase enzyme system [1]. Glyoxalase I [S-lactoylglutathione methylglyoxal-lyase (isomerising), EC 4.4.1.5] is a $\mathrm{Zn}^{2+}$ metalloenzyme which catalyses the conversion of the thiohemiacetal non-enzymatically formed between glutathione (GSH) and $\alpha$-ketoaldehydes to the thioester of the corresponding $\alpha$-hydroxy acid. The hydrolysis of the latter to lactic acid and free GSH is catalysed by a complementary enzyme, glyoxalase II [1]. The suggestion that this action is related to the regulation of cell division [2-4] has stimulated interest in this enzyme system and its mechanism as an approach to antineoplastic agents [5-7].

The coenzyme contributes significantly to the mechanism of action. Only GSH, a few related tripeptides [8] and $N$-acyl derivatives $[9,10]$ are active and capable of molecular recognition by the enzyme. Other sulphydryl-containing compounds including the glycyl esterified derivative [9] of GSH are inactive. Suggestions have been made that this may be due to binding to an arginal residue [11], however an alternative explanation may be the presence of a high steric constraint in this region on the enzyme. In view of the importance of the carboxyl groups to binding and the uncertainty associated with their roles we have used the glutathione analogues 1-5 shown in scheme 1 to study these regions on the enzyme.

\section{MATERIALS AND METHODS}

Glyoxalase I (grade IV from yeast) and substrates were purchased from Sigma. Methylglyoxal was purified by removal of acidic contaminants by ion-exchange chromatography and stock concentrations were determined by a modification of [12]. Glutathione derivative 1 was prepared as in [6]. Derivative 3 was prepared from 1 by a modification of procedures in [9] and 2 by treatment of 3 with saturated $\mathrm{NH}_{3} / \mathrm{CH}_{3} \mathrm{OH}$. 
<smiles>[R]OC(=O)CCC(=O)NC(CSCc1ccc(Br)cc1)C(=O)NC(N)C(=O)O</smiles>

(1) $\mathrm{R}=-\mathrm{OH} \quad \mathrm{R}^{\prime}=-\mathrm{OH}$

(2) $\mathrm{R}=-\mathrm{NH}_{2} \quad \mathrm{R}^{\prime}=-\mathrm{OH}$

(3) $\mathrm{R}=-\mathrm{OCH}_{3} \quad \mathrm{R}^{\prime}=-\mathrm{OH}$

(4) $\mathrm{R}=-\mathrm{NH}_{2} \quad \mathrm{R}^{\prime}=-\mathrm{NH}_{2}$

(5) $\mathrm{R}=-\mathrm{OCH}_{3} \quad \mathrm{R}^{\prime}=-\mathrm{OCH}_{3}$

Scheme 1.

Derivatives 5 and 4 were prepared by $\mathrm{HBr} /$ $\mathrm{CH}_{3} \mathrm{COOH} N$-deprotection of $N$-benzoyloxycarbonyl-S-(4-bromobenzyl)glutathione dimethyl ester and diamide derivatives prepared from the free acid precursor [13] as above for 3 and 2. Derivatives were found to be pure by TLC, elemental analysis and structures confirmed by NMR [13] and IR. Assignments of glycyl modification in derivatives 2 and 3 were made by anaerobic hydrazinolysis of the peptides at $110^{\circ} \mathrm{C}$ for $24 \mathrm{~h}$ [14]. Separation of the hydrazinolysis products of $2,3,1$ as well as glycyl and $\gamma$-glutamyl hydrazide standards by cellulose or silica chromatography developed in butanol/acetic acid/water (12:3:5) and visualised with ninhydrin allowed differential comparisons and assignment of 2 and 3 to be madc. Stock solutions of derivatives 1-3 were prepared in purified dimethyl sulphoxide; final concentrations of this co-solvent in the assay media were kept to $<1 \%(\mathrm{v} / \mathrm{v})$ at which value there is no detectable rate effect on the assay of yeast glyoxalase I. Enzyme assays were performed at $25^{\circ} \mathrm{C}, 0.05 \mathrm{M}$ phosphate buffer, pH 6.6 as reported in [10]. Thiohemiacetal concentrations present in the equilibrated mixture of GSH and methylglyoxal were calculated by using a value of $3.1 \mathrm{mM}$ for the dissociation constant of the thiohemiacetal at pH 6.6 [4]. Substrate concentrations were taken as 0.5 -times the appropriate thiohemiacetal concentrations to allow for the diastereomeric selectivity of glyoxalase I [15] assuming the selectivity is present at $\mathrm{pH}$ 6.6.

To diagnose the inhibition type, both Lineweaver-Burk $\left(1 / V_{0}\right.$ vs $\left.1 / S_{0}\right)$ and Dixon $\left(1 / V_{0}\right.$ vs $I)$ plots were scrutinised. Computations were carried out on a memory expanded ZX81 microcomputer using pre-recorded least-squares linear regression analysis programmes.
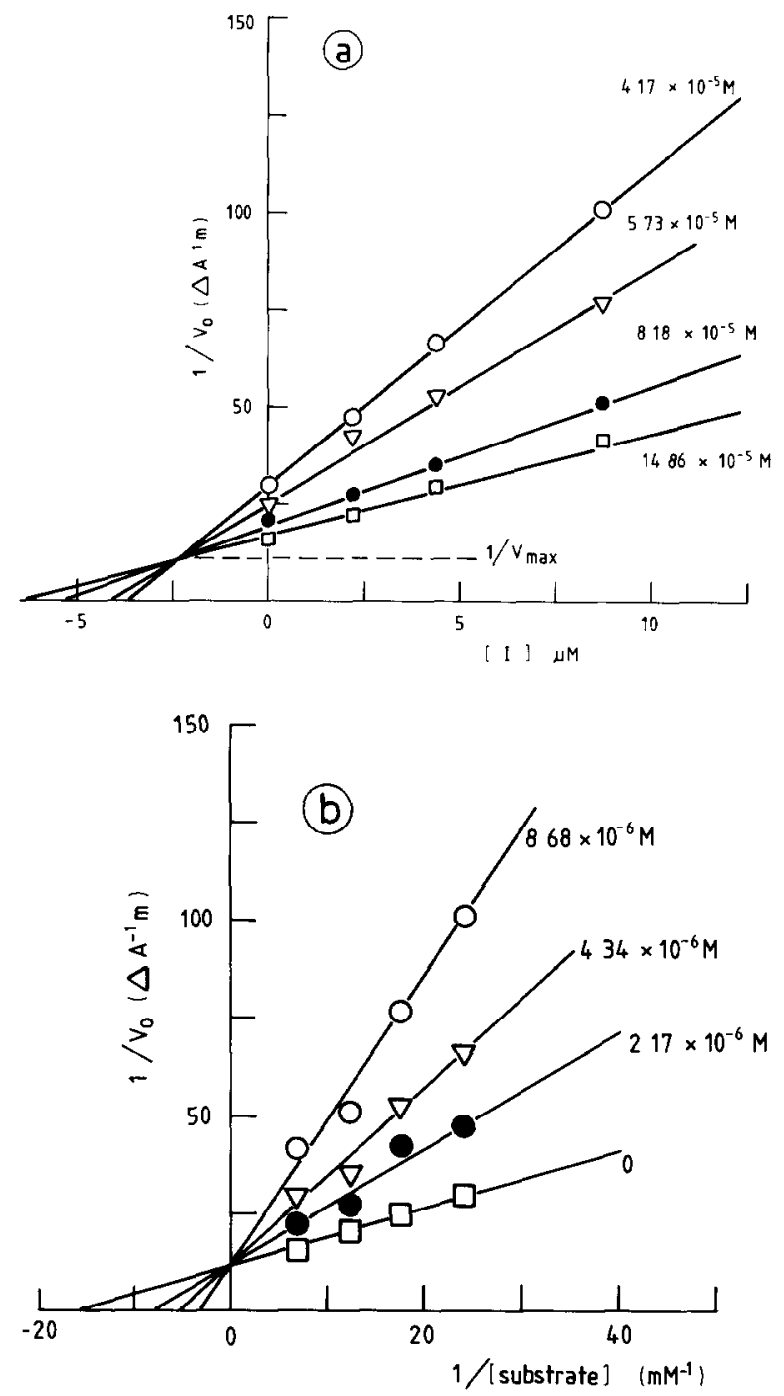

Fig.1. (a) Dixon and (b) Lineweaver-Burk plots at pH 6.60 (in $0.05 \mathrm{M}$ phosphate buffer) and $25^{\circ} \mathrm{C}$ for the inhibition of glyoxalase I by derivative 2 . The points are experimental and the lines theoretical [(a) marked with the appropriate substrate concentration used and (b) with the appropriate inhibitor concentration used] assuming linear competitive inhibition. 


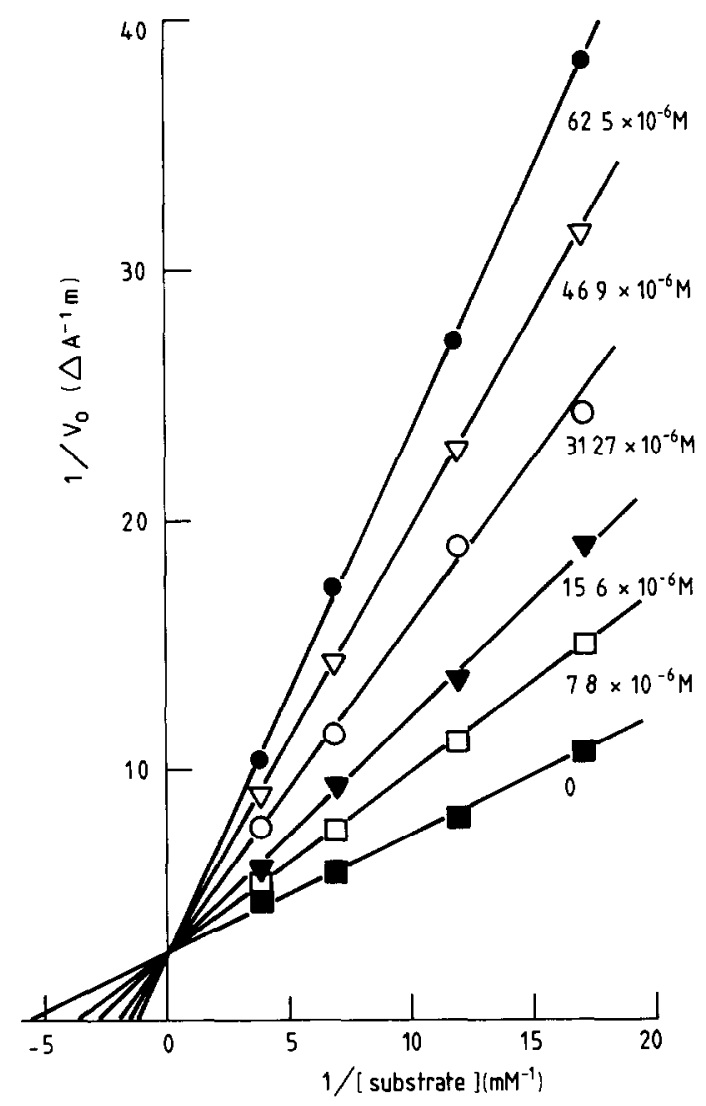

Fig.2. Lineweaver-Burk plot for derivative 3. The points are experimental, lines are theoretical (marked with the appropriate inhibitor concentration used) assuming linear competitive inhibition.

\section{RESULTS}

In agreement with previous reports $\mathbf{1}$ is a linear competitive inhibitor of yeast glyoxalase $\mathrm{I}$ at $\mathrm{pH}$ 6.60 and $25^{\circ} \mathrm{C}$. Derivatives 2 and 3 were linearly competitive with the thiohemiacetal of methylglyoxal and GSH by both Lineweaver-Burk $\left(1 / V_{0}\right.$ vs $\left.1 / S_{0}\right)$ and Dixon ( $1 / V_{0}$ vs $\left.I\right)$ criteria, the results for 2 and 3 being depicted in figs 1 and 2 , respectively. The $K_{\mathrm{i}}$ values of 2 and 3 were found to be $2.35 \pm 0.67$ and $19.7 \pm 0.94 \mu \mathrm{M}$ respectively (see table 1) by calculation from the mean intersections on the $1 / V_{\max }$ axis of the appropriate Dixon plot. Derivatives 4 and 5 were both inhibitors of glyoxalase I, however the weak inhibition obtained coupled with the high absorption of these derivatives at $240 \mathrm{~nm}$ only allowed an estimate of $50 \%$ inhibition $\left(I_{50}\right)$ to be calculated. The values of $K_{\mathrm{i}}$ for 4 and 5 were $520.7 \pm 9.1$ and $537.1 \pm$ $8.9 \mu \mathrm{M}$, respectively (see table 1 ). This was obtained by plotting the ratio of $V_{0} / V_{\mathrm{i}}$ vs $I$ and graphical extrapolation to $50 \%$ at thiohemiacetal concentrations of $8.35 \times 10^{-5}$ and $5.9 \times 10^{-5} \mathrm{M}$ allowing for diastereomeric selectivity. The maximum experimentally observed inhibition was $40 \%$.

\section{DISCUSSION}

From the results the linear competitive inhibition of derivatives 2 and 3 (table 1) indicates that these molecules probably bind to the same site as derivatives 1 and simple $S$-blocked glutathiones. The fact that there is no significant difference in $K_{\mathrm{i}}$

Table 1

Inhibition of yeast glyoxalase I by carboxyl-substituted glutathione derivatives

\begin{tabular}{|c|c|c|c|c|c|}
\hline Compound & $\mathbf{R}$ & $\mathbf{R}^{\prime}$ & $K_{\mathrm{i}}(\mu \mathrm{M})$ & Ratio & $\begin{array}{c}K_{\mathrm{i}}: \mathrm{R}=\mathrm{R} \\
K_{\mathrm{i}}: \mathrm{R}=\mathrm{R}^{\prime}=\mathrm{OH}\end{array}$ \\
\hline 1 & $-\mathrm{OH}$ & $-\mathrm{OH}$ & $2.2 \pm 0.75^{\mathrm{a}}$ & & 1 \\
\hline 2 & $-\mathrm{NH}_{2}$ & $-\mathrm{OH}$ & $2.35 \pm 0.67^{\mathrm{a}}$ & & 1.07 \\
\hline 3 & $-\mathrm{OCH}_{3}$ & $-\mathrm{OH}$ & $19.7 \pm 0.94^{\mathrm{a}}$ & & 8.95 \\
\hline 4 & $-\mathrm{NH}_{2}$ & $-\mathrm{NH}_{2}$ & $520.7 \pm 9.1^{b}$ & & 237 \\
\hline 5 & $-\mathrm{OCH}_{3}$ & $-\mathrm{OCH}_{3}$ & $537.1 \pm 8.9^{b}$ & & 244 \\
\hline
\end{tabular}

a Prepared in dimethyl sulphoxide: concentration $1 \%(\mathrm{v} / \mathrm{v})$

b Prepared in $\mathrm{H}_{2} \mathrm{O}$ 
on amidation of the glycyl carboxyl group comparison of glutathione derivatives 2 with 1 clearly argues that it is not involved in an electrostatic bond with an arginal residue on the enzyme as previously suggested [11]. The 8.95 -fold weakening in $K_{\mathrm{i}}$ on methylation comparison of 3 and 2 probably reflects a steric constraint indicative of a group binding in a cleft shielded by the protein structure to one on the surface exposed to the solvent. In addition, such a constraint may reflect the presence of a hydrogen bond between the glycyl carboxyl group and a group on the enzyme. Recent NMR studies on glyoxalase I $[16,17]$ have identified an extended Y-shaped conformation for enzyme-bound glutathione derivatives in which the glycyl carboxyl group is adjacent to where the catalytic base may be located. It is therefore possible that a hydrogen bond exists between the glycyl carboxyl group and the catalytic base, presumed to be a histidine residue [18]. Studies undertaken on carboxyl-modified free-sulphydryl glutathiones are in agreement with the above studies and show that the methyl ester derivatives are inactive as substrates $[9,10]$ with this enzyme, probably due to poor binding.

Derivatives 4 and 5 are both weak inhibitors of glyoxalase I. Assuming linear competitive inhibition for these derivatives the 237 -fold weakening in $K_{\mathrm{i}}$ on comparison of derivatives 4 with 2 shows that the $\mathrm{Glu} \mathrm{COO}^{-}$group contributes significantly to the binding of glutathione to the enzyme. A value of $13.5 \mathrm{~kJ} \cdot \mathrm{mol}^{-1}\left(3.2 \mathrm{kcal} \cdot \mathrm{mol}^{-1}\right)$ at $25^{\circ} \mathrm{C}$ is a minimum estimate calculated for the binding energy of this favourable interaction using $\Delta \Delta G=$ $R T \ln \Delta \mathrm{p} K_{\mathrm{i}}$. This result agrees with electrostatic interaction of the $\mathrm{Glu}^{\mathrm{COO}^{-}}$with a cationic group located within the enzyme in a region of low dielectric constant [10]. The most likely candidate for this group is a single arginal residue shown to be present in the GSH-binding site [11]. Of the two alternative conformations for glutathione (class I and class II) [17], our data do not preclude the class I structure previously disfavoured probably due to the assignment of interaction of the arginine residue with the glycyl group. Of the two conformations, this study in conjunction with kinetic studies undertaken on the free-SH form of derivative $\mathbf{2}$ a substrate of yeast glyoxalase I favour a class $I$ conformation as summarised schematically in scheme 2 in which the glycyl group may be

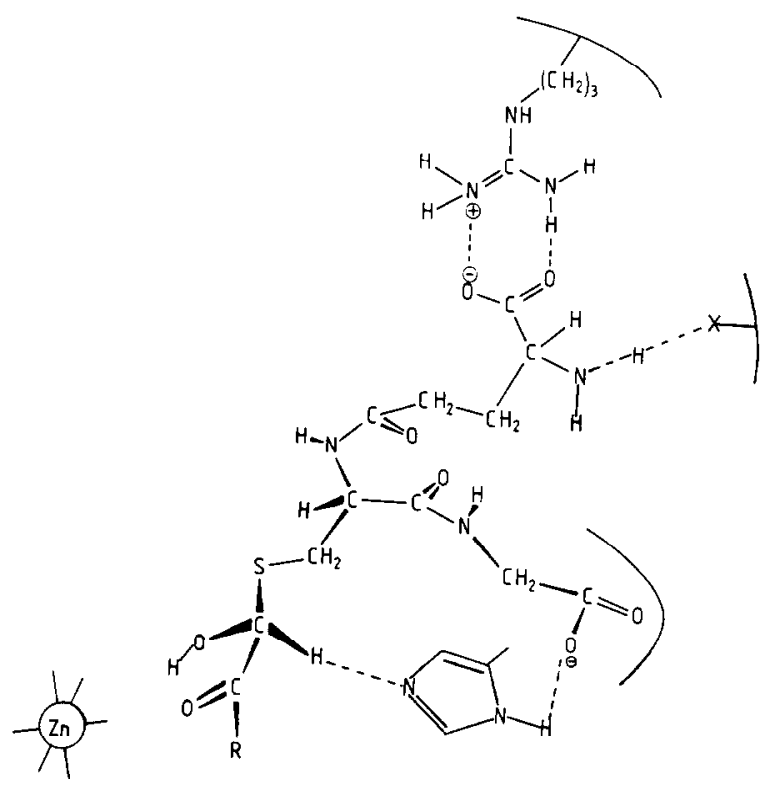

Scheme 2.

hydrogen-bonded to the catalytic base.

This result as well as those obtained by the use of these derivatives with glutathione transferase clearly shows the importance of evaluation of both amide and ester derivatives when assessing the role of the $\mathrm{COOH}$ group with respect to binding.

\section{ACKNOWLEDGEMENT}

Thanks are expressed to Miss Elaine Bagley for her help with this manuscript.

\section{REFERENCES}

[1] Knox, W.E. (1960) in: The Enzymes (Boyer, P.D. et al. eds) vol.2, p.253 et seq, Academic Press, New York.

[2] Szent-Gyorgi, A. (1968) Science 161, 988-990.

[3] Szent-Gyorgi, A. (1968) in: Bioelectronics, pp.63-76, Academic Press, New York.

[4] Vince, R. and Daluge, S. (1971) J. Med. Chem. 14, 35-37; Vince, R., Daluge, S. and Wadd, W.B. (1974) J. Med. Chem. 14, 402-404.

[5] Vince, R., Wolf, M. and Sandford, C. (1973) J. Med. Chem. 16, 951-953.

[6] Lyon, P.A. and Vince, R. (1977) J. Med. Chem. 16, 951-953. 
[7] Douglas, K.T. and Shinkai, S. (1985) Angew. Chem. Int. Ed. Engl. 24, 31-44.

[8] Carnegie, P.R. (1963) Biochem. J. 89, 471; Behrens, O.K. (1941) J. Biol. Chem. 141, 503; Kogl, F. and Akherman, A.M. (1946) Recl Trav. Chim. Pays-Bas 65, 225; Wieland, T., Pfleiderer, G. and Lau, H.H. (1956) Biochem. Z. 327, 393.

[9] Vander Jagt, D.L. and Han, L.-P.B. (1973) Biochemistry $12,5161-5167$.

[10] Douglas, K.T., Al-Timari, A., D'Silva, C. and Gohel, D.I. (1982) Biochem. J. 207, 323-332.

[11] Schasteen, C.S. and Reed, D.J. (1983) Biochim. Biophys. Acta 742, 419-425.

[12] Bergmeyer, H.-U. (1974) in: Methods of Enzymatic Analysis, 2nd Engl. edn, pp.283-284, Academic Press, New York.
[13] D'Silva, C., Al-Timari, A. and Douglas, K.T. (1982) Biochem. J. 207, 329-332.

[14] Schroeder, W.A. (1972) Methods Enzymol. 25B, 138.

[15] Brown, C., Douglas, K.T. and Ghobt-Sharif, J. (1981) J. Chem. Soc. Chem. Commun., 944-946.

[16] Sellin, S., Rosevear, P.R., Mannervik, B. and Mildvan, A.S. (1982) Fed. Proc. 41, 1152; (1982) J. Biol. Chem. 257, 10023-10029.

[17] Rosevear, P.R., Sellin, S., Mannervick, B., Kunitz, I.D. and Mildvan, A.S. (1984) J. Biol. Chem. 259, 11436-11447.

[18] Hall, S.S., Doweyko, A.M. and Jordan, F. (1978) J. Am. Chem. Soc. 100, 5934-5939. 